\title{
NON-ISOTHERMAL THERMAL ANALYSIS OF DIFFERENT ORIGINATED LIGNOCELLULOSIC BIOMASS, NON-TREATED AND TORREFIED BY MICROWAVE TREATMENT
}

\author{
Alexandr Arshanitsa ${ }^{1,2}$, Anna Andersone ${ }^{1,2}$, Galina Telysheva ${ }^{1,2}$ \\ ${ }^{1}$ EkoKompozit Ltd, Latvia; ${ }^{2}$ Latvian State Institute of Wood Chemistry, Latvia \\ arshanitsa@edi.lv, andersone@edi.lv, telysheva@gmail.com
}

\begin{abstract}
The effect of microwave (mw) assisted torrefaction on the combustion performance of three lignocellulosic feedstocks, namely, softwood, wheat straw and peat was studied by means of non-isothermal thermal analysis realized in air atmosphere. Each feedstock was torrefied at $200{ }^{\circ} \mathrm{C}, 250{ }^{\circ} \mathrm{C}$ and $300{ }^{\circ} \mathrm{C}$. using a laboratory scale microwave torrefactor of original construction. The differential thermal gravimetric curves of all non-treated and torrefied samples are separated into two main stages responsible for oxidative volatilization and char combustion. The degradation of wheat straw derived fuel was more complicated. Two separated peaks were observed in char combustion profiles for this feedstock, both non-treated and torrefied. The apparent activation energy of conversion for each degradation stage and its average value for processing were calculated by integration of the Arrhenius equation using Coats-Redfern methods. The averaged activation energy of the conversion of torrefied samples exceeded that of non-treated samples for all feedstocks under study and varied in the range of $132-211 \mathrm{~kJ} \cdot \mathrm{mol}^{-1} \mathrm{vs} 75-152 \mathrm{~kJ} \cdot \mathrm{mol}^{-1}$ for non-treated biomass. The calculated activation energy of non-treated and torrefied samples increased in the rank: peat <softwood < wheat straw. Although non-torrefied biomass decomposed at lower energy input, the total heat output as a result of thermal oxidation of torrefied feedstocks increased up to $62-83 \%$ vs that of non-treated biomass.
\end{abstract}

Keywords: lignocellulosic, microwave, torrefaction, thermal gravimetric analysis, activation energy.

\section{Introduction}

Solid-fuel combustion represents a major segment of modern energy technology, finding its primary applications in large-scale electricity generation, industrial heating, steam generation, destruction of waste, domestic heating etc. [1]. The novel economic and environmental factors leading to the diversification of solid fuel restrict the combustion of fossil coals and increase the application of renewable solid fuels. The target of the European Commission climate and energy framework is a $32 \%$ share of renewable energy in 2030, gradually substituting the fossil fuels by renewable feedstock [2]. In this context, lignocellulosic biomass, including agricultural residues, is in focus of interest due to their huge growing potential [3]. Direct substitution of coal with biomass has revealed inferior properties of biomass such as the lower energy density and higher hydrophobicity, resulting in storage complication and lower efficiency of energy conversion. Thermal-chemical pre-treatment of lignocellulosic biomass, including mild pyrolysis/torrefaction, is a promising route to recover energy from biomass and to improve the fuel characteristics of the solid fraction obtained. The use of microwave (MW) irradiation at the frequency of $2.45 \mathrm{GHz}$ as an alternative source of energy instead of conventional heating for the realization of different chemical processes, including biomass processing, has been under active study in the last decade [4]. The main advantages of MW-based technologies include selective and volumetric heating of substrate with low thermal conductivity, and the ability to start and stop the process instantaneously that improve processing control [5]. In this work, the effect of mw torrefaction on the combustion behaviour of lignocellulosic feedstocks of different origination, including natural softwood, wheat straw as an agricultural residue, was studied using thermal gravimetric (TG) analysis, differential thermal gravimetric (DTG) analysis and differential thermal analysis (DTA). Peat, due to its high availability, is still recognized as a prospective solid fuel, although it belongs to a category between fossil and renewable and therefore was used also as an object of investigation. The characteristics of reactivity, activation energy of conversion and heat amounts produced a result of combustion of torrefied feedstocks vs that for non-treated samples were in focus.

\section{Materials and methods}

Commercial softwood pellets with a diameter of $6.0 \mathrm{~mm}$, wheat straw and peat pellets, both with a diameter of $8.0 \mathrm{~mm}$, and a water content of $7 \%, 10 \%$ and $9 \%$, respectively, torrefied at temperatures of $200{ }^{\circ} \mathrm{C}, 250^{\circ} \mathrm{C}$ and $300{ }^{\circ} \mathrm{C}$ for each were used as an object of investigation. A MW laboratory device of original construction equipped with a magnetron (mw power $850 \mathrm{~W}$ at $2.45 \mathrm{GHz}$ ), a coaxial waveguide, a rotating reactor $(\mathrm{V}=1.3 \mathrm{l})$ placed in a tubular resonator $(\mathrm{V}=40 \mathrm{l})$, a condenser tool for the collection 
of the liquid fraction was applied for biomass processing [6]. The duration of processing at given temperature was 20 minutes. The element composition was measured according to LVS EN 15104:2011. HHV was calculated based on elemental analysis data [6].

Element composition in terms of $\mathrm{O} / \mathrm{C}$ and $\mathrm{H} / \mathrm{C}$ atomic ratios and

Table 1 higher heating values (HHV) of biomass samples under study

\begin{tabular}{|c|c|c|c|c|c|c|c|c|c|}
\hline \multirow{2}{*}{$\begin{array}{c}\text { MW } \\
\text { treatment, } \\
{ }^{\circ} \mathrm{C}\end{array}$} & \multicolumn{3}{|c|}{ Softwood } & \multicolumn{3}{|c|}{ Wheat straw } & \multicolumn{3}{|c|}{ Peat } \\
\hline & $\mathrm{O} / \mathrm{C}$ & $\mathbf{H} / \mathrm{C}$ & $\begin{array}{c}\text { HHV, } \\
\text { MJ· } \mathbf{k g}^{-1}\end{array}$ & $\mathrm{O} / \mathrm{C}$ & $\mathbf{H} / \mathrm{C}$ & $\begin{array}{c}\text { HHV, } \\
\text { MJ·kg }\end{array}$ & $\mathrm{O} / \mathrm{C}$ & H/C & $\begin{array}{l}\text { HHV, } \\
\text { MJ·kg-1 }\end{array}$ \\
\hline $\begin{array}{c}\text { Non- } \\
\text { treated }\end{array}$ & 0.64 & 1.46 & 19.9 & 0.68 & 1.49 & 18.4 & 0.53 & 1.18 & 20.9 \\
\hline 200 & 0.62 & 1.43 & 20.2 & 0.65 & 1.43 & 18.9 & 0.47 & 1.12 & 22.0 \\
\hline 250 & 0.55 & 1.33 & 21.5 & 0.58 & 1.37 & 19.6 & 0.31 & 1.03 & 25.4 \\
\hline 300 & 0.41 & 1.13 & 24.5 & 0.22 & 0.89 & 26.0 & 0.24 & 0.88 & 26.9 \\
\hline
\end{tabular}

Thermal analysis was performed using a Metler Toledo Star System TGA/SDTA 851e instrument. Temperature range of scanning $25-650^{\circ} \mathrm{C}$ at a constant heating rate of $10 \mathrm{~K} \cdot \mathrm{min}^{-1}$, the air flow rate $50 \mathrm{~cm}^{3} \cdot \mathrm{min}^{-1}$. Sample weight $\sim 10 \mathrm{mg}$. Before tests, non-treated and torrefied pellets were homogenized in a Mixer BALL Mill MM200 (Retch) and oven dried in vacuum at $50{ }^{\circ} \mathrm{C}$. Each sample was tested twice. The relative error of parallel measurements did not exceed $1.5 \%$. For all samples under study, the temperature of $5 \%$ weight loss was defined as the starting temperature of active degradation. Burnout temperature, determined as a temperature, where the weight loss rate reaches $1 \% \cdot \mathrm{min}^{-1}$ at the terminal phase of the DTG, was defined as a degradation termination temperature [7]. The value of the temperature corresponding to the minimum degradation rate between two peaks of DTG profiles was used for separation of different stages of biomass conversion.

The reactivity $\left(\mathrm{R}_{\mathrm{M}}\right)$ of biomass was calculated based on the DTG profile [8].

$$
R_{M}=100 \sum R_{\max } / T_{\max }
$$

where $R_{\max }$ - peak of the maximum loss rate, $\% \cdot \mathrm{s}^{-1}$;

$T_{\max }$ - corresponding peak of temperature, ${ }^{\circ} \mathrm{C}$.

The apparent activation energy $\left(\mathrm{E}_{\mathrm{A}}\right)$ of the non-isothermal conversion of biomass was determined based on TG experimental data using the Coats-Redfern integration method, which allows to convert the Arrhenius equation into a linear regression form (Eq. 2), assuming that biomass degradation is described by the first-order Arrhenius law [9]:

$$
-\ln \left[\frac{g(\alpha)}{T^{2}}\right]=\frac{E_{A}}{R} \cdot \frac{1}{T}-\ln \left(\frac{A R}{\beta E_{A}}\right)
$$

where $E_{A}$-activation energy, $\mathrm{kJ} \cdot \mathrm{mol}^{-1}$;

$T$ - temperature, $\mathrm{K}$;

$A$ - frequency factor, $\mathrm{s}^{-1}$;

$R$ - universal gas constant $\left(8.3145 \cdot \mathrm{J} \cdot \mathrm{mol}^{-1} \cdot \mathrm{K}^{-1}\right)$;

$\beta$ - heating rate $\left(10 \mathrm{~K} \cdot \mathrm{min}^{-1}\right)$;

$g(\alpha)=-\ln (1-\alpha)$.

$\alpha$ - conversion, defined as:

$$
\alpha=\frac{m_{0-} m_{t}}{m_{0}-m_{f}}
$$

where $m_{o}$-sample weight before conversion, $\mathrm{mg}$;

$m_{f}$ - sample weight after conversion, $\mathrm{mg}$;

$m_{t}$ - sample weight at any moment of conversion, $\mathrm{mg}$.

For the different stage of biomass conversion, plotting the left-hand side of (Eq. 2), which includes $g(\alpha)$ vs $1 / T$, gives $E_{\mathrm{A}}$ from the slope (Fig. 1d). The average value of activation energy was calculated as follows:

$$
E_{A}^{a v}=\sum_{i=0}^{n} E_{A}^{i} X_{i}
$$


where $E_{A}^{i}$-activation energy for the given separated stage, $\mathrm{kJ} \cdot \mathrm{mol}^{-1}$;

$X_{i}-$ normalized weight fraction of biomass converted in this stage.

The amount of energy released as a result of non-treated and torrefied biomass combustion was estimated using the DTA results as described in [3]. It was taken into account that the area enclosed by the DTA curve is a dimensionless value directly proportional to the heat produced.

\section{Results and discussion}

It was shown that the DTG curves of all samples under study, non-treated and torrefied, are separated into three stages: low temperature zone $\left(50-100^{\circ} \mathrm{C}\right)$ attributed to the removal of traces of moisture and two high temperature stages responsible for the main biomass degradation [8]. It is recognized that the first of them in the range of $200-370^{\circ} \mathrm{C}$ is attributed to the main lignocellulosic component volatilization and the second in the range of $370-500{ }^{\circ} \mathrm{C}$ is responsible for char combustion [3;7-9] (Fig. 1).
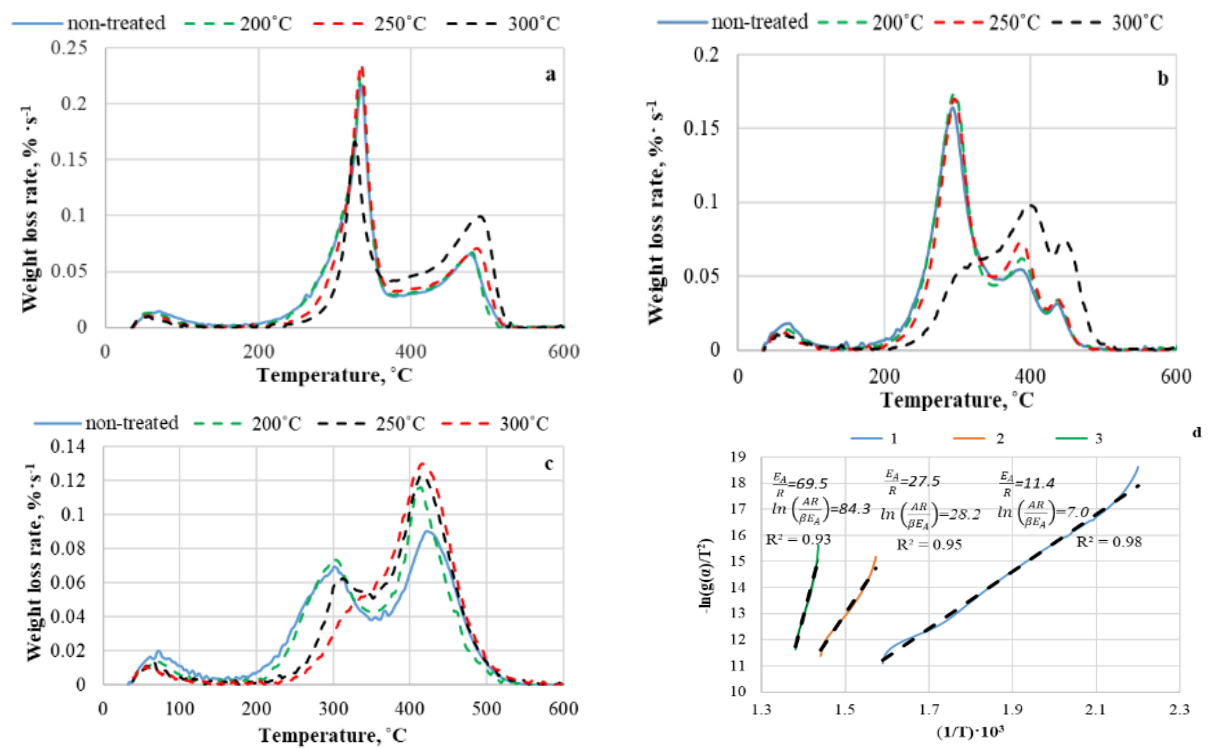

Fig. 1. DTG profiles in air for non-treated and MW torrefied biomass of different origin: softwood (a), wheat straw (b) and peat (c); linear regression in Coats-Redfern coordinate for different degradation zones of non-treated wheat straw (1 - volatilization stage;

\section{2, 3 - char combustion stage) (d)}

In contrast to the case of two other biomasses, two-step char combustion of wheat straw was observed from its DTG profiles, testifying the different reactions responsible for each step. It proves the data that, besides the direct oxidation of lignocellulosic char with $\mathrm{CO}_{2}$ formation, in reality, the process of char combustion is more complicated and consists of a series of sorption and desorption processes of $\mathrm{O}_{2}$ by active sites of carbon [10]. Therefore, depending on the char properties (surface area, extent of graphitization), different parallel reactions will proceed. As an example, the kinetic calculation performed in this paper, assuming that single, not parallel reactions take place in each conversion stage, has shown that the apparent activation energy of the first and second steps of char combustion of wheat straw consists of 228 and $575 \mathrm{~kJ} \cdot \mathrm{mol}^{-1}$, respectively, testifying the different reaction mechanism that occurred for each step.

It was shown by TG data that, with increasing torrefaction temperatures, the weight loss of biomass as a result of oxidative volatilization steadily decreased with increasing, on the contrary, the portion of biomass converted as a result of char combustion. This regularity was more pronounced for wheat straw (Table 2). However, the extent of volatilization was the least for peat samples. It is explained by the fact that, in comparison with the non-degraded lignocellulosic biomass of straw and softwood, the peat formed from the biomass of terrestrial plants partly decomposed under conditions of limited air access and in high temperature (initial stage of coalification) was partly carbonized (Table 1). The initial temperature of active degradation (5\% weight loss on TG curves) of torrefied biomass was significantly 
shifted towards higher temperature in comparison with non-treated biomass. The temperature of the char combustion step beginning was similar for both torrefied and non-treated samples (Fig. 1; Table 2). Due to the significant increase in the temperature of active decomposition start and the insufficient increase in the burnout temperature, the average conversion rate calculated from DTG profiles of torrefied softwood and wheat straw was slightly higher in comparison with that of non-treated biomass and varied in the range of $5.9-6.5 \times 10^{-3} \% \cdot \mathrm{s}^{-1}$ vs $\sim 5.3 \times 10^{-3} \% \cdot \mathrm{s}^{-1}$ for raw biomass. At the same time, for torrefied peat, the average rate of weight loss increased more significantly, from $3.8 \% \times 10^{-3} \% \cdot \mathrm{s}^{-1}$ to $6.5^{\%} \times 10^{-3} \% \cdot \mathrm{s}$ ${ }^{1}$. Reactivity index $(\mathrm{Rm})$, which is an empiric index directly related to the peaks rate of biomass degradation from DTG profiles and is inversely proportional to the related temperatures, was similar for non-treated and torrefied biomass, slightly decreasing for the sample torrefied at $300{ }^{\circ} \mathrm{C}$. In this respect, raw wood biomass revealed itself as the most reactive (Table 2).

The values of apparent activation energy calculated based on experimental data for different stages of biomass degradation testified that the energy input needed for volatilization of torrefied softwood significantly increased vs those of non-treated biomass, but changed a little for the char oxidation stage. In most cases torrefied wheat straw and peat biomass have higher $\mathrm{E}_{\mathrm{A}}$ of both stages. The calculated average values of activation energy of conversion $\left(E_{A}{ }^{a v}\right)$ of torrefied softwood, wheat straw and peat varied in the range of $131.6-159.9 \mathrm{~kJ} \cdot \mathrm{mol}^{-1}, 176.0-205.2 \mathrm{~kJ} \cdot \mathrm{mol}^{-1}$ and $129.9-141.9 \mathrm{~kJ} \cdot \mathrm{mol}^{-1} \mathrm{vs}$ $117.9 \mathrm{~kJ} \cdot \mathrm{mol}^{-1}, 125.4 \mathrm{~kJ} \cdot \mathrm{mol}^{-1}$ and $74.6 \mathrm{~kJ} \cdot \mathrm{mol}^{-1}$ for non-treated biomass, respectively (Table 2). This clearly indicates that the degradation/conversion of torrefied biomass needs a higher energy input.

Table 2

\section{Combustion characteristics of non-treated and torrefied biomass according to TG/DTG analysis}

\begin{tabular}{|c|c|c|c|c|c|c|c|c|}
\hline \multirow{2}{*}{$\begin{array}{c}\text { MW } \\
\text { treatment, } \\
{ }^{\circ} \mathrm{C}\end{array}$} & \multicolumn{3}{|c|}{ Oxidative degradation } & \multicolumn{3}{|c|}{ Char combustion } & \multicolumn{2}{|c|}{ Overall process } \\
\hline & $\begin{array}{c}\text { Range, } \\
{ }^{\circ} \mathrm{C}\end{array}$ & $\begin{array}{c}\Delta m_{1}, \\
\%\end{array}$ & $\begin{array}{c}E_{A}{ }^{1}, \\
\mathbf{k J} \cdot \mathbf{m o l}^{-1}\end{array}$ & $\begin{array}{c}\text { Range, } \\
{ }^{\circ} \mathrm{C}\end{array}$ & $\begin{array}{c}\Delta \mathbf{m}_{\mathbf{2}}, \\
\%\end{array}$ & $\begin{array}{c}E_{A}{ }^{2}, \\
\mathbf{k J} \cdot \mathbf{m o l}^{-1}\end{array}$ & $\begin{array}{c}E_{A}{ }^{a v} \\
\mathbf{k J} \cdot \mathbf{m o l}^{-1}\end{array}$ & $R_{m} \times 10^{-2}$ \\
\hline \multicolumn{9}{|c|}{ Softwood } \\
\hline n.t & $212-372$ & 67.1 & 108.7 & $373-507$ & 32.9 & 135.2 & 117.9 & 3.5 \\
\hline 200 & $237-377$ & 65.7 & 126.3 & $378-501$ & 34.3 & 146.5 & 131.6 & 3.6 \\
\hline 250 & $269-377$ & 60.6 & 168.3 & $378-512$ & 39.4 & 136.2 & 155.6 & 3.7 \\
\hline 300 & 290-372 & 40.5 & 208.0 & $373-519$ & 59.5 & 127.2 & 159.9 & 3.2 \\
\hline \multicolumn{9}{|c|}{ Wheat straw } \\
\hline n.t & $177-357$ & 75.9 & 94.8 & $358-453$ & 24.1 & 228.4 & 152.2 & 2.2 \\
\hline 200 & $229-357$ & 72.2 & 120.9 & $358-454$ & 27.8 & 318.6 & 176.0 & 2.4 \\
\hline 250 & $240-352$ & 64.3 & 135.6 & $353-451$ & 35.7 & 345.5 & 210.5 & 2.5 \\
\hline 300 & $264-357$ & 34.0 & 92.6 & $358-482$ & 66.0 & 263.1 & 205.2 & 2.0 \\
\hline \multicolumn{9}{|c|}{ Peat } \\
\hline n.t & $106-357$ & 47.0 & 38.0 & $358-496$ & 53 & 107.3 & 74.6 & 2.2 \\
\hline 200 & 223-357 & 43.1 & 105.3 & $358-486$ & 58.9 & 142.6 & 129.9 & 2.6 \\
\hline 250 & $265-357$ & 28.9 & 155.7 & $358-497$ & 71.1 & 135.6 & 141.3 & 2.5 \\
\hline 300 & $282-357$ & 21.6 & 175.1 & $357-500$ & 78.5 & 132.2 & 141.9 & 2.4 \\
\hline
\end{tabular}

n.t - non-treated; $\Delta m_{1}+\Delta m_{2}=100 \%$

The combustion behaviour of non-treated and torrefied fuels in terms of heat produced was studied by the DTA method (Fig. 2).

Two regions responsible for endothermal $\left(\Delta H_{0}\right)$ and exothermal processes $\left(\Delta H_{1}\right.$ and $\left.\Delta H_{2}\right)$ are presented in DTA profiles of each sample under study. The area of endothermal regions is proportional to the energy required for liberation of volatiles to promote the exothermal effect of their oxidation. In this region, the energy balance is shifted towards input energy, which changes to output energy, when an onset temperature ( $\left.T_{\text {onset }}\right)$ is reached and exothermic temperature appears (Fig. 2).

It was established that the onset temperature value was lower for torrefied biomass (Fig. 2) and, correspondingly, the exothermic occurred at a lower actual mass loss in comparison with the case of non-treated biomass. Exemplified by wheat straw, the initial step of its combustion occurred at $13.6 \%$ of mass loss, and decreased to $12 \%, 7.8 \%$ and $3 \%$ for wheat straw torrefied at $200{ }^{\circ} \mathrm{C}, 250{ }^{\circ} \mathrm{C}$ and $300{ }^{\circ} \mathrm{C}$, 
respectively. A similar effect was observed for softwood and peat. The results testified that, in comparison with torrefied biomass at combustion of raw fuel, a rather big portion of volatiles was removed without producing of heat. It can be explained by rather lower calorific values of volatiles dissolved by non-combustible products $\left(\mathrm{H}_{2} \mathrm{O}, \mathrm{CO}_{2}\right.$, acetic acids etc.), which are removed from raw lignocellulosic biomass at the beginning of thermal degradation, resulting in less effective utilization of the raw biomass potential for heat production instead of torrefied biomass.
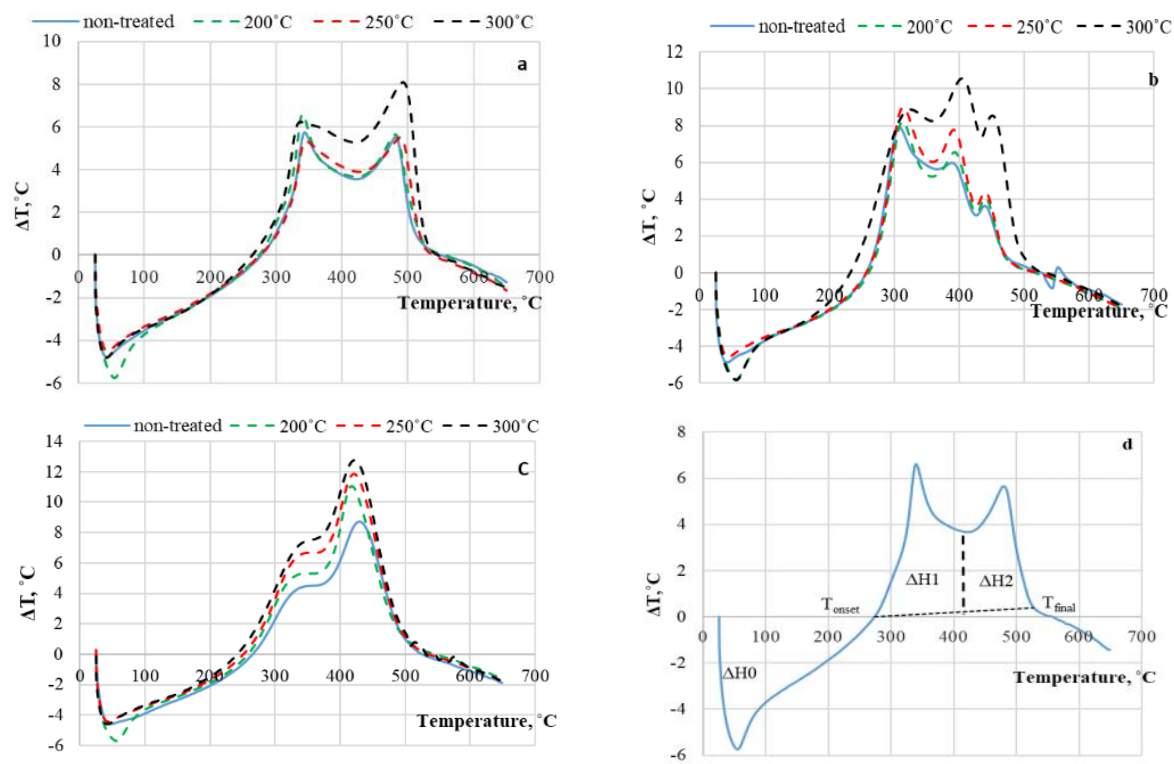

Fig. 2. DTA profiles in air for non-treated and MW torrefied biomass of different origin: softwood (a), wheat straw (b) and peat (c); principle of heat effect calculation using DTA exemplified by non-treated softwood ( $\Delta H$ - normalized area; $T_{\text {onset }}$ and $T_{\text {final }}-$ first and last point of integration range, respectively)

In comparison with non-treated softwood and wheat straw biomass, the portion of heat produced as a result of the char combustion stage of torrefied samples was steadily increased with decreasing the relative input of the volatile combustion stage in the overall heat balance (Table 3). Most of the increment of char combustion by $63-65 \%$ was established for peat independently of the MW treatment temperature. Obviously, this can be explained by the presence of humic substances in the peat composition, strongly differing on structures and, therefore, by the thermodegradation behaviour from its lignocellulosic precursors. In accordance with TG/DTG results, with the increase in the temperature of MW torrefaction, the yield of volatiles steadily decreased for all types of biomass (Table 2). Nevertheless, the area of the DTA regions responsible for volatile oxidation increased. This testified that, together with the increase of the fixed carbon content in torrefied biomass, the calorific values of volatiles also increased. Both effects are responsible for the overall heat output of torrefied biomass combustion, which is superior to that obtained by non-treated softwood, and peat combustion by up to $62-6 \%$ and up to $83 \%$ for wheat straw (Table 3 ).

Table 3

Differential thermal analysis of non-treated and torrefied biomass

\begin{tabular}{|c|c|c|c|c|c|c|c|}
\hline \multirow{2}{*}{$\begin{array}{c}\text { MW } \\
\text { treatment, } \\
{ }^{\circ} \mathrm{C}\end{array}$} & \multicolumn{3}{|c|}{ Volatile combustion } & \multicolumn{3}{|c|}{ Char combustion } & \multirow{2}{*}{$\begin{array}{c}\text { Total } \\
\Delta \boldsymbol{H}_{\text {tot }}{ }^{M W /} / \\
\Delta \boldsymbol{H}_{\text {tot }}{ }^{n} . t\end{array}$} \\
\hline & $\overline{\Delta H_{1}}$ & $\begin{array}{c}\Delta \boldsymbol{H}_{1}{ }^{M W /} / \\
\Delta \boldsymbol{H}_{1}{ }^{n . t}\end{array}$ & $\begin{array}{l}\Delta \boldsymbol{H}_{1} / \\
\Delta \boldsymbol{H}_{\text {tot }}\end{array}$ & $\Delta \boldsymbol{H}_{2}$ & $\begin{array}{l}\Delta \boldsymbol{H}_{2}{ }^{M W} / \\
\Delta \boldsymbol{H}_{2}{ }^{n . t}\end{array}$ & $\begin{array}{l}\Delta \boldsymbol{H}_{2} / \\
\Delta \boldsymbol{H}_{\text {tot }}\end{array}$ & \\
\hline \multicolumn{8}{|c|}{ Softwood } \\
\hline n.t & 54.1 & 1.00 & 0.58 & 39.8 & 1.00 & 0.42 & 1.00 \\
\hline 200 & 63.2 & 1.17 & 0.60 & 42.1 & 1.06 & 0.40 & 1.12 \\
\hline 250 & 65.1 & 1.20 & 0.57 & 49.3 & 1.24 & 0.43 & 1.22 \\
\hline 300 & 78.3 & 1.45 & 0.51 & 75.0 & 1.88 & 0.49 & 1.63 \\
\hline
\end{tabular}


Table 3 (continued)

\begin{tabular}{|c|c|c|c|c|c|c|c|}
\hline \multirow{2}{*}{$\begin{array}{c}\text { MW } \\
\text { treatment, } \\
{ }^{\circ} \mathrm{C}\end{array}$} & \multicolumn{3}{|c|}{ Volatile combustion } & \multicolumn{3}{|c|}{ Char combustion } & \multirow{2}{*}{$\begin{array}{c}\text { Total } \\
\Delta \boldsymbol{H}_{\text {tot }}{ }^{M W} \\
\Delta \boldsymbol{H}_{\text {tot }}{ }^{n}{ }^{\prime} t\end{array}$} \\
\hline & $\Delta H_{1}$ & $\begin{array}{c}\Delta \boldsymbol{H}_{1}{ }^{M W /} / \\
\Delta \boldsymbol{H}_{1}{ }^{n \cdot t}\end{array}$ & $\begin{array}{l}\Delta \boldsymbol{H}_{1} / \\
\Delta \boldsymbol{H}_{\text {tot }}\end{array}$ & $\Delta \boldsymbol{H}_{2}$ & $\begin{array}{l}\Delta \boldsymbol{H}_{2}{ }^{M W /} / \\
\Delta \boldsymbol{H}_{2}{ }^{n \cdot t}\end{array}$ & $\begin{array}{l}\Delta \boldsymbol{H}_{2} / \\
\Delta \boldsymbol{H}_{\text {tot }}\end{array}$ & \\
\hline \multicolumn{8}{|c|}{ Wheat straw } \\
\hline n.t & 60.7 & 1.00 & 0.54 & 51.7 & 1.00 & 0.46 & 1.00 \\
\hline 200 & 59.1 & 0.97 & 0.51 & 56.3 & 1.09 & 0.49 & 1.02 \\
\hline 250 & 67.9 & 1.12 & 0.52 & 63.7 & 1.23 & 0.48 & 1.17 \\
\hline 300 & 86.6 & 1.43 & 0.43 & 120.0 & 2.32 & 0.58 & 1.83 \\
\hline \multicolumn{8}{|c|}{ Peat } \\
\hline n.t & 41.5 & 1.00 & 0.35 & 78.3 & 1.00 & 65.4 & 1.00 \\
\hline 200 & 50.6 & 1.22 & 0.36 & 88.3 & 1.13 & 63.6 & 1.16 \\
\hline 250 & 62.0 & 1.49 & 0.37 & 104.7 & 1.34 & 62.8 & 1.39 \\
\hline 300 & 68.3 & 1.65 & 0.35 & 126.0 & 1.61 & 64.8 & 1.62 \\
\hline
\end{tabular}

n.t - non-treated; $\Delta H_{\text {tot }}=\Delta H_{1}+\Delta H_{2}$

\section{Conclusions}

1. A higher energy input is needed for thermal oxidative conversion of softwood, wheat straw and peat torrefied by microwave treatment vs that of non-treated biomass. The average values of activation energy for non-treated biomass varied in the range of $75-118 \mathrm{~kJ} \cdot \mathrm{mol}-1$ vs 132 $211 \mathrm{~kJ} \cdot \mathrm{mol}-1$ for microwave torrefied samples. The activation energy of conversion is increased in the rank: peat $<$ softwood $<$ wheat straw. This series corresponds to both initial and torrefied biomass.

2. Both factors, namely, increasing of the calorific values of the formed volatiles and increasing of the fixed carbon content in torrefied biomass are responsible for the up to $62-83 \%$ higher heat output obtained by their thermal oxidation in comparison with that of non-treated biomass.

\section{Acknowledgements}

The authors would like to acknowledge the financial support from the European Regional funding of project No. 1.1.1.1/19/A/010.

\section{References}

[1] Hurt R. Structure, properties, and reactivity of solid fuels. International symposium on combustion, vol. 27 , issue 2 , 1998, pp. 2887-2904. DOI: 10.1016/S0082-0784(98)80148-3

[2] European Commission, 2030 climate \& energy framework. [online] [10.01.2021] Available at: https://ec.europa.eu/clima/policies/strategies/2030_en

[3] Bridgeman T.G., Jones J.M., Shield I., Williams P.T. Torrefaction of reed canary grasses, wheat straw, and willow to enhance solid fuel qualities and combustion properties. Fuel, vol. 87, 2008, pp. 844-856.

[4] Mitani T. Recent progress on microwave processing of biomass for bioenergy production. Journal of Japan Petroleum Institute, vol. 61, 2018, pp. 113-120.

[5] Budarin V., Clark J., Lanigan B., Shuttleworth P., Macquarrie D. Microwave assisted decomposition of cellulose: a new thermochemical route of biomass exploitation. Biresource Technology, vol. 110, 2010, pp. 3776-3779.

[6] Arshanitsa A., Akishin Y., Zile E., Dizhbite T., Solodovnik V., Telysheva G. Microwave treatment combined with conventional heating of plant biomass pellets in a rotated reactor as a high rate process for solid biofuel manufacture, Renewable Energy, 2016, vol. 91, pp. 386-396, DOI: 10.1016/j.renene.2016.01.080.

[7] El May Y., Jegurim M., Dorge S., Trouve G., Said R. Study of thermal behavior of different date palm residues: Characterization and devolatilization kinetics under inert and oxidative atmospheres, Energy, vol. 44, 2012, pp. 702-709.

[8] Okorogweit E. Combustion analysis and devolatization kinetics of Gmelina, Mango, Neem, and Tropical Almond woods under oxidative condition, International Journal of Renewable Energy Research, vol. 5, 2015, pp. 1025-1033. 
[9] Shen D.K., Gu S., Luo K.H., Bridgwater A.V., Fang M.X. Kinetic study on thermal decomposition of woods in oxidative environment, Fuel, vol. 88, 2009, pp. 1024-1030.

[10] Di Blasi C. Combustion and gasification rate of lignocellulosic chars, Progress in Energy and Combustion Science, vol. 35, 2009, pp.121-140. 